\title{
The Need for CAM Research Training
}

\author{
Claudia M. Witt ${ }^{\mathrm{a}}$ Klaus Linde \\ a Institute for Social Medicine, Epidemiology and Health Economics, Charité University Medical Center, Berlin, Germany \\ ${ }^{b}$ Centre for Complementary Medicine Research, Department for Internal Medicine II, Technical University of Munich, Germany
}

In recent years, there has been a substantial increase in the amount and quality of research on complementary and alternative medicine (CAM) and according to a survey, German medical universities have an interest CAM research [1]. Nevertheless, compared to other fields of study, the number of researchers in Europe specialising in CAM has remained very small, whereas the number of physicians practicing CAM is still growing. This discrepancy may have several causes. It is conceivable, for example, that many physicians who practice CAM trust more in experience and expert knowledge than in the results of clinical trials. In addition, research methodology has become increasingly sophisticated, and the formal hurdles related to ethical approval and quality assurance are high. Research is conducted primarily by universities or industry, leaving individual physicians with little opportunity to gather experience or apply for funding.

To further improve the quality of CAM research and to increase its practical relevance, it is crucial that ambitious young professionals be equipped with both practical and methodological skills. Treating patients and conducting research are not mutually exclusive, and for some CAM practitioners the combination of both may be an interesting option. However, barriers are high for young physicians who want to get a first taste of research, and outside of a university career they do not have the opportunity to receive proper training in research methodology. To date, courses on evidence-based medicine have focused on the critical appraisal of clinical studies, but have not taught students how to conduct them. Other summer schools on epidemiology focus almost exclusively on epidemiological studies and spend very little time on clinical research. Therefore, to meet the special challenges in CAM research [2] and to motivate more CAM practitioners to pursue research, specially tailored training is needed.

With this in mind, and after some years of discussion, we have attempted to take a first step in this direction by offering an introductory summer school on CAM research methods. Upon completing the programme, participants will have a basic knowledge of a range of study designs (e.g. randomised trials, observational studies, single-case research, economic studies, meta-analyses) and specific methodological issues related to selecting participants, randomising patients, choosing controls, ensuring proper blinding, and measuring outcomes, etc. A pilot course was offered during the summer of 2007 and was made possible thanks to encouragement and funding from the Robert Bosch Foundation. In a 4-day seminar, the 18 participants learned which study types are best suited to answer which research questions. The participants were also trained to appraise clinical research studies critically, to understand the statistical findings of clinical studies, to perform simple sample-size calculations and basic statistical analyses, and to design their own study while taking into account specific problems related to CAM. The summer school will be distinguished by its practically oriented training, an e-learning platform, a congenial atmosphere, and very low costs for participants. The two main course instructors (Claudia Witt and Klaus Linde) participated in all lectures so as to provide a range of experience and to include questions raised in the lectures in subsequent lessons. In addition, the classes in statistics were taught by a statistician with experience in CAM (Rainer Lüdtke). The participants in the first summer school, which was conducted in German, were from Germany (14), Austria (2), and Switzerland (2). The mean age was 43 years (range $26-60$ years) and $56 \%$ of the participants were women. Nearly all of the participants had conducted previous research or planned their first clinical studies. Some participants were educators, themselves, and were thus in a position to disseminate the knowledge they acquired in the summer school. The programme was evaluated by participants using a validated questionnaire, and its overall quality was rated as very high.

\begin{tabular}{ll}
\hline KARGER & $\oplus$ 2008 S. Karger GmbH, Freiburg \\
Fax +49 7614520714 & Accessible online at: \\
$\begin{array}{l}\text { E-mail Information@Karger.de } \\
\text { www.karger.com }\end{array}$ & www.karger.com/fok
\end{tabular}

Claudia M. Witt, MD, MBA

Institute for Social Medicine, Epidemiology and Health Economics

Charité University Medical Center, Berlin

10098 Berlin, Germany

Tel. +49 30450529002 , Fax 450529902

E-mail claudia.witt@charite.de 
After this successful pilot course, which was limited to German-speaking physicians, we decided to open up the summer school to a broader European audience and foster international networking among participants. The next summer school, which will also be funded by the Robert Bosch Foundation, will be conducted in English and will take place from September 3-7, 2008. For more information, please see www.charite.delepidemiologie/english/news or www.mието. med.tu-muenchen.de.

Activities like the summer school described here can represent only a first step on the long road to professionalising CAM research. In the United States, efforts to professionalise CAM research began several years ago. For example, the National Center of Complementary and Alternative Medicine (NCCAM) offers a variety of comprehensive training programmes and educational opportunities (http://nccam.nih.gov/ training/opportunities/). In addition a center for evidencebased complementary and alternative medicine (EBCAM) practice was estabished [3]. It seems unlikely, however, that public funds supporting CAM training in Europe will match those available in the United States anytime soon. Some funding opportunities for training are available from the European Union, but the small CAM research community has to compete for these with many other institutions working in more established fields. It is likely that European researchers in CAM will have to build highly efficient networks capable of establishing top-quality training facilities under limited resources. Integration into CAM training during medical studies [4] and a co-ordinated post graduated programme of basic and more specialised courses might represent a first step, followed at the next level by Master's and $\mathrm{PhD}$ study programmes. The International Society for Complementary Medicine Research (ISCMR; www.iscmr.org/) could be a good candidate organisation for coordinating these activities.

It would be unrealistic to expect the number of people engaged in active CAM research to become very large in the future. Indeed, considering that CAM is primarily about caring for patients, this cannot be the primary aim. Nevertheless, we are convinced that high quality research is crucial to all areas of health care, and that it should be pursued by bright individuals with a solid background in the sciences and strong practical skills. Supporting these individuals and the professionalisation of CAM should be one of the chief goals of all scientists in the field.

\section{References}

Brinkhaus B, Joos S, Lindner M, Kohnen R, Witt C, Willich SN, Hahn EG: Integration of complementary and alternative medicine in German medical schools contradictions between the opinions of decision makers and the status quo. Forsch Komplementärmed Klass Naturheilkd 2005;12:139-143.

2 Jonas WB: Building an evidence house: challenges and solutions to research in complementary and alternative medicine. Forsch Komplementärmed Klass Naturheilkd 2005;12:159-167.

3 Coulter ID: Evidence Based Complementary and Alternative Medicine: Promises and Problems. Forsch Komplementärmed 2007;14:102-108

4 Witt CM, Brinkhaus B, Willich SN: Teaching complementary and alternative medicine in a reform curriculum. Forsch Komplementärmed Klass Naturheilkd 2006;13:342-348 